\title{
Perlindungan Lahan Pertanian Pangan Berkelanjutan dalam Mendukung Pelestarian Subak
}

\author{
Made Putra Suryawan \\ Kelompok Ahli Pembangunan Daerah Provinsi Bali \\ email: detrasuryawan@gmail.com
}

\begin{abstract}
In the Government Regulation Number 23 Year 1982 concerning irrigation, in Article 1 (h) it is affirmed the meaning of "Subak", namely as a socio-agrarian customary law community, being religious that has historically grown and developed as an organization in the field of water use at the farm level. Subak cannot be separated from food plantation and agricultural land, "krama subak" and its relationship with the Creator of the universe (the God). Subak in Bali is based on the philosophy of "Tri Hita Karana" which can be seen as a system because subak contains three main components, namely "parhyangan (God), pawongan (man), and palemahan (nature), which are closely related to each other. "Tri Hita Karana" consists of components of human relations with God / creator, human relations with humans, and human relations with their natural environment. In subak irrigation cannot be separated from food cropland, so that sustainable agricultural land will have an impact on subak's sustainability in Bali.
\end{abstract}

Keywords: agricultural land, food, sustainable, subak.

\section{PENDAHULUAN}

Subak sebagai lembaga tradisional yang bersifat sosio agraris religius yang sudah sangat membudaya dikenal di seluruh pelosok dunia dan bahkan disebut sebagai salah satu organisasi petani pemakai air yan paling cangih di dunia. Dalam perjalanan waktu organisasi subak di Bali dari generasi ke generasi dan dengan situasi kondisi yang berbeda-beda telah mengalami reformasi apalagi setiap tahun terjadi alih fungsi lahan pertanian pangan yang tidak terkendali, sehingga hal ini akan mempengaruhi kelestarian subak di Bali. Kemudian dengan terbitnya Undang-undang Nomor 41 Tahun 2009 tentang perlindungan lahan pertanian pangan berkelanjutan merupakan salah satu dasar hukum untuk melestarikan keberadaan subak di Bali.

Lahan pertanian pangan berkelanjutan adalah bidang lahan pertanian yang ditetapkan untuk dilindungi dan dikembangkan secara konsisten guna 
Kalau kita perhatikan di Provinsi Bali dari data lima tahun terakhir terjadi alih fungsi lahan pertanian pangan seluas $2.145 \mathrm{Ha}$ yaitu dari luas lahan sawah di Bali tahun 2012 seluas 81.625 Ha menjadi 79.480 Ha pada tahun 2016, secara rinci dapat dilihat pada Tabel 1.

Tabel 1

Perkembangan Luas Lahan Sawah di Provinsi Bali Tahun 2012 dan 2016 Per Kabupaten/Kota (Ha)

\begin{tabular}{|c|c|c|c|}
\hline \multirow[b]{2}{*}{ No. } & \multirow[b]{2}{*}{ Kabupaten/Kota } & & \\
\hline & & 2012 & 2016 \\
\hline 1. & Buleleng & 10.992 & 10.707 \\
\hline 2. & Jembrana & 6.836 & 6.311 \\
\hline 3. & Tabanan & 22.435 & 21.714 \\
\hline 4. & Badung & 10.243 & 10.006 \\
\hline 5. & Denpasar & 2.597 & 2.479 \\
\hline 6. & Gianyar & 14.732 & 14.420 \\
\hline 7. & Bangli & 2.910 & 2.886 \\
\hline 8. & Klungkung & 3.845 & 3.843 \\
\hline 9. & Karangasem & 7.154 & 7.114 \\
\hline \multirow[t]{5}{*}{ Bali } & 2016 & - & 79.480 \\
\hline & 2015 & - & 80.542 \\
\hline & 2014 & - & 80.506 \\
\hline & 2013 & - & 81.360 \\
\hline & 2012 & 81.625 & 81.625 \\
\hline
\end{tabular}

Sumber: Bappeda Litbang Provinsi Bali Tahun 2016, Data Bali Membangun.

\section{Permasalahan Alih Fungsi Lahan Sawah dan Pelestarian Subak}

Dalam kurun waktu tahun 2012-2016 sudah terjadi alih fungsi lahan sawah seluas $2.145 \mathrm{Ha}$, hal ini sangat besar artinya dalam penurunan produksi. Berarti terjadi kehilangan produksi padi, palawija dan hortikultura yang sangat besar, di samping itu juga setiap tahun terjadi peningkatan jumlah penduduk hal ini menyebabkan terganggunya ketahanan pangan Daerah. Beberapa faktor 
penyebab terjadinya alih fungsi lahan pertanian pangan dalam pelestarian subak di Bali dapat diinventarisir sebagai berikut.

- Adanya degradasi dan fragmentasi lahan sawah yaitu salah satunya karena adanya sistem bagi waris akibat bertambahnya jumlah penduduk.

- Faktor ekonomi (inisiatif berusahatani relatif rendah) serta Pajak Bumi dan Bangunan (PBB) relative sangat tinggi sehingga hal ini menyebabkan alih fungsi lahan pertanian menjadi non pertanian.

- Lemahnya penegakan hukum bidang pengendalian alih fungsi lahan pertanian.

- Adanya land consolidation sehingga hal ini dapat merusak tatanan insfrastruktur irigasi, menyebabkan irigasi sangat terganggu/terbatas.

- Adanya kebutuhan tanah untuk kegiatan non pertanian yang terus meningkat seperti untuk perumahan, kawasan industri/perdagangan, fasilitas umum,

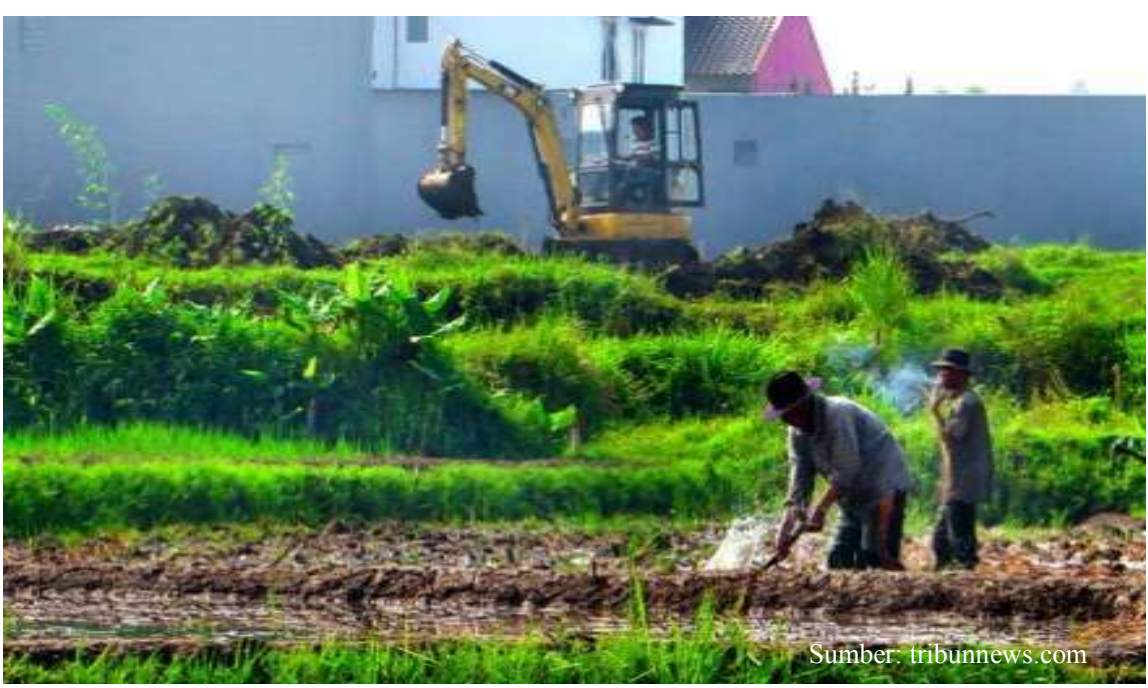
pembangunan sektor pariwisata dan lain-lain yang tidak terkendali.

- Belum adanya dasardasar hukum untuk mengendalikan alih fungsi lahan pertanian dalam rangka melestarikan lahan pertanian yang berkelanjutan.

\section{KERANGKA BERPIKIR}

Berdasarkan kondisi dan permasalahan terebut diatas maka maka alih fungsi lahan pertanian sangat mempengaruhi tingkat produksi dan penyediaan pangan di Bali pada khususnya dan Nasional pada umumnya. Terkait dengan hal ini pemerintah telah menerbitkan dasar-dasar hukum dalam rangka memberikan perlindungan terhadap lahan pertanian pangan berkelanjutan yang dapat dipakai/ menindaklanjuti produk-produk hukum turunannya sehingga di Bali ada luasan lahan pertanian pangan abadi yang dapat dipertahankan, 
sehingga subak di Bali akan menjadi lestari dan berkelanjutan. Adapun produk hukum yang sudah diterbitkan oleh pemerintah berupa Undang-undang dengan produk hukum turunanya berupa Peraturan Pemerintah serta Peraturan Menteri Pertanian Republik Indonesia sebagai berikut.

1. Undang-undang Republik Indonesia Nomor 26 Tahun 2007 tentang Penataan Ruang (Lembaran Negara Republik Indonesia Tahun 2007 Nomor 68, Tambahan Lembaran Negara Republik Indonesia Nomor 4725).

2. Undang-undang Republik Indonesia Nomor 41 Tahun 2009 tentang Perlindungan Lahan Pertanian Pangan Berkelanjutan, sebagai amanat Undang-undang pada point 1.

3. Peraturan Pemerintah Republik Indonesia Nomor 12 Tahun 2012 tentang Insentif Perlindungan Lahan Pertanian Pangan Berkelanjutan.

4. Peraturan Pemerintah Republik Indonesia Nomor 25 Tahun 2012 tentang Sistem Informasi Lahan Pertanian Pangan Berkelanjutan.

5. Peraturan Pemerintah Republik Indonesia Nomor 30 Tahun 2012 tentang Pembiayaan Perlindungan Lahan Pertanian Pangan Berkelanjutan.

6. Peraturan Menteri Pertanian Republik Indonesia Nomor : 41/Permentan/OT/140/9/2009 tentang Kriteria Teknis Kawasan Peruntukan Pertanian.

7. Peraturan Daerah Nomor 16 Tahun 2009 tentang Rencana Tata Ruang Wilayah ( RTRW ) Provinsi Bali.

Undang-undang Nomor 41 Tahun 2009 tentang Lahan Pertanian Pangan Berkelanjutan mempunyai azas dan tujuan antara lain.

- Melindungi Kawasan dan Lahan Pertanian Pangan secara Berkelanjutan

- Menjamin tersedianya Lahan Pertanian Pangan Berkelanjutan

- Mewujudkan Kemandirian, Ketahanan dan Kedaulatan Pangan

- Melindungi lahan pertanian milik petani

- Meningkatkan kesejahteraan petani dan masyarakat

- Meningatkan perlindungan dan pemberdayaan petani

- Meningkatkan penyediaan lapangan kerja bagi kehidupan yang layak

- Mempertahankan keseimbangan ekologi

- Mewujudkan revitalisasi pertanian. 


\section{PENUTUP DAN REKOMENDASI}

Dengan disusun dan ditetapkan Peraturan Daerah Kabupaten/Kota dan Peraturan Daerah Provinsi Bali tentang Perlindungan Lahan Pertanian Pangan Berkelanjutan sebagai tindak lanjut pelaksanaan Undang-undang Nomor 41 Tahun 2009 tentang Perlindungan Lahan Pertanian Pangan Berkelanjutan maka subak di Bali sebagai warisan budaya akan menjadi lestari.

Bertitik tolak dari permasalahan dan program pelestarian subak di Bali maka ada beberapa hal yang dapat direkomedasikan sebagai berikut. Pertama, landasan Filosofi Subak di Bali adalah "Tri Hita Karana" maka "palemahan" (areal sawah) sebagai unsur pelemahan subak tidak bisa dipisahkan dengan kegiatan dan kehidupan sistem subak di Bali, untuk itu perlu di tetapkan lahan pertanian pangan abadi agar subak dapat lestari sepanjang masa.

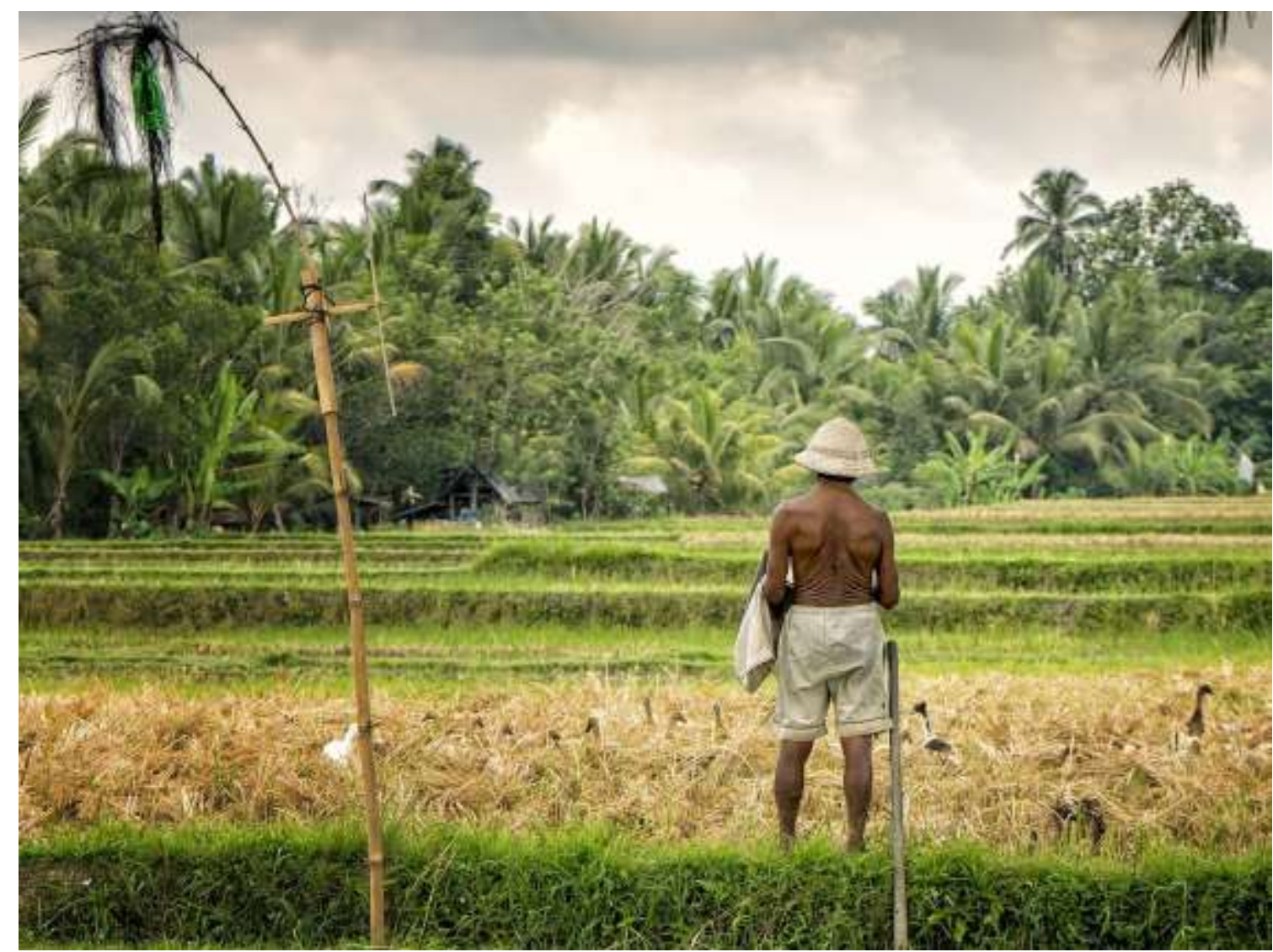

Kedua, dalam upaya peningkatan produksi sebagai pelaksanaan kegiatan subak maka perlu diterapkan pembangunan pertanian ramah 
lingkungan dengan penerapan pertanian organik sehingga lahan subak menjadi lestari.

Ketiga, sehubungan dengan Undang-undang Nomor 41 Tahun 2009 tentang Perlindungan Lahan Pertanian Pangan Berkelanjutan telah diundangkan oleh Pemerintah dengan segala PeraturanPemerintah yang merupakan turunannya maka Pemerintah Provinsi Bali agar segera menyusun dan menetapkan Peraturan Daerah (Perda) tentang Perlindungan Lahan Pertanian Pangan Berkelanjutan untuk mendukung Pelestarian Subak.

Keempat, sebelum Perda pada point 3 tersebut disusun dan ditetapkan maka Kabupten/kota segera menetapkan lahan pertanian pangan sebagai lahan pertanian pangan abadi yang selanjutnya ditetapkan denga Peraturan Daerah Kabupaten/kota sebagai dasar Penetapan Peraturan Daerah Provinsi Bali.

Kelima, Peraturan Daerah Nomor 16 Tahun 2009 tentang Rencana Tata Ruang Wilayah (RTRW) Provinsi Bali agar dipakai juga sebagai acuan dalam penyusunan Perda Perlindungan Lahan Pertanian Pangan Berkelanjutan di Provinsi Bali.

Keenam, lahan-Lahan pertanian pangan yang telah ditetapkan sebagai lahan pertanian pangan abadi dalam perlindungan lahan pertanian pangan berkelanjutan di Kabupaten/Kota se Provinsi Bali agar diberikan insentif.

Ketujuh, pemberian Dana Bantuan Sosial agar diberikan secara berkelanjutan kepada seluruh Subak (subak sawah dan subak abian) di Provinsi Bali sehingga subak tetap ajeg dan lestari bahkan terus ditingkatkan karena Subak merupakan warisan Budaya Dunia.

\section{DAFTAR PUSTAKA}

Bappeda Litbang Provinsi Bali. 2016. Data Bali Membangun.

Dinas Pekerjaan Umum Provinsi Dati I Bali. 1998. Subak di Bali.

Dinas Kebudayaan Provinsi Dati I Bali. 1998. Tuntunan Subak di Bali.

Peraturan Pemerintah Republik Indonesia Nomor 12 Tahun 2012, tentang Insentif Perlindungan Lahan Pertanian Pangan Berkelanjutan.

Peraturan Pemerintah Republik Indonesia Nomor 25 Tahun 2012, tentang Sistem Informasi Lahan Pertanian Pangan Berkelanjutan. 
Peraturan Pemerintah Republik Indonesia Nomor 30 Tahun 2012, tentang Pembiayaan Perlindungan Lahan Pertanian Pangan Berkelanjutan.

Suryawan, Made Putra. 2014. "Alih Fungsi Lahan Sawah Ancam Pembangunan Pertanian Tanaman Pangan di Bali, Pokok-pokok Pikiran dan Kajian Bidang Pembangunan di Provinsi Bali”.

Suryawan, Made Putra. 2017. "Subak dalam Era Modernisasi, Pokok-pokok Pikiran dan Kajian Bidang Pembangunan di Provinsi Bali”.

Undang-undang Republik Indonesia Nomor 41 Tahun 2009 tentang Perlindungan Lahan Pertanian Pangan Berkelanjutan. 